Revista Perspectivas Online: Exatas \& Engenharias Dezembro de 2017, Vol.7, no 19 , p. 36-41 ISSN: $2236-885 \mathrm{X}$ (Online)

DOI: $10.25242 / 885 \times 7192017948$

\title{
ANÁLISE EXPERIMENTAL DO SISTEMA MASSA-MOLA ATRAVÉS DA LEI DE HOOKE
}

\author{
Anastasiia Melnyk $^{1^{*}}$ e Luciano Nascimento ${ }^{2}$
}

\begin{abstract}
RESUMO
MELNYK, A; NASCIMENTO, L. Análise Experimental do Sistema de Massa-Mola através da Lei de Hooke. Perspectivas Online: Exatas \& Engenharias, v. 7, n.19, p.36-41,2017.

Neste artigo, apresentamos as medidas efetuadas e as análises verificando a Lei de Hooke num sistema massa-mola. Análise gráfica dos resultados, selecionamos determinadas faixas de dados onde as

constantes elásticas do equipamento têm um comportamento considerado constante. Após a análise dos resultados, obteve-se o valor da constante elástica da mola utilizada, respectivamente.
\end{abstract}

Palavras-chave: Lei de Hooke; constante elástica; mola.

\begin{abstract}
In this article, we present the measured values and analysis verifying Hooke's Law in a massspring system. graphical analysis of the results, certain selected data tracks where the elastic

constants of the machine have a constant behavior considered. After analyzing the results, we obtained the value of the spring constant use respectively.
\end{abstract}

Keywords: Hooke's law; elastic constant; spring.

\footnotetext{
${ }^{1}$ Universidade Federal da Paraíba (UFPB) - Programa de Pós-Graduação em Letras (PPG-CLA) - Cidade Universitária, Caixa Postal: 5008, João Pessoa, PB, CEP: 58059-900, Brasil.

${ }^{2}$ Universidade Federal da Paraíba (UFPB) - Departamento de Física (DF/CCEN) - Cidade Universitária, Caixa Postal: 5008, João Pessoa, PB, CEP: 58059-900, Brasil.

(*)e-mail: anastasiia.ufpb@gmail.com

Data de chegada: 22/05/2016 Aceito para publicação: 07/03/2017
} 


\section{INTRODUÇÃO}

Um dos experimentos mais tradicionais empregados em aulas da disciplina de física geral e experimental é aquela que verifica a relação linear entre a força aplicada em um sistema e sua elongação (deformação), ou seja, a lei de Hooke (Laburú ; Almeida, 1998). Geralmente, o equipamento convencional muito empregado para a realização deste experimento constitui-se, basicamente, de uma mola de aço e massas (discos médios de bronze) padrões aferidas. Assim, propomos apresentar um estudo baseado numa montagem real que descreve suscitamenta a Lei de Hooke através de dados experimentais obtidos por meio de um gráfico linear que ilustrará o comportamento da constante elástica do sistema na região empírica trabalhada, para este equipamento não atingindo a região de deformação elástica (Bonjorno et al.,1999). Essa forma de apresentação se justifica na medida em que, havendo uma menor flutuação da constante elástica para cada massa, haverá diretamente uma relação linear entre a elongação e a respectiva força aplicada, para a verificação da lei de Hooke. Durante essa avaliação, mostraremos a necessidade de se trabalhar numa faixa mais conveniente de dado experimental (massas) para cada equipamento, a fim de que a lei de Hooke possa ser adequadamente observada, conforme mencionamos. O objetivo desse trabalho é verificar a lei de Hooke, e determinação da constante elástica de uma mola.

\section{TEORIA}

Todos os corpos sob ação de uma força de tração ou de compressão deformam-se, uns mais, outros menos. Ao aplicarmos uma força em uma mola helicoidal, ao longo de seu eixo, ela será alongada ou comprimida. Se, ao cessar a atuação da força externa, a mola recuperar a sua forma e tamanho originais, dizse que a deformação é elástica. Em geral, existem limites de força a partir dos quais acontece uma deformação permanente, sendo denominada região de deformação plástica. Dentro do limite elástico há uma relação linear entre a força externa aplicada e a deformação. É o caso de uma mola helicoidal pendurada por uma de suas extremidades enquanto que a outra sustenta um corpo de massa $\mathrm{m}$, provocando uma elongação $\mathrm{x}$ na mola. Na presente situação considera-se que a massa da mola seja muito menor do que a massa presa a sua extremidade, ou seja, a massa da mola será desprezável, comparada com $\mathrm{m}$. Uma mola ao sofrer deformações acumula energia potencial elástica. Esta energia possui uma força associada que é chamada força restauradora, ou força elástica, que é proporcional ao deslocamento da posição de equilíbrio. Esta força é dada por (Halliday et al.,1996):

$$
F=k \cdot x
$$

Essa equação é descreve a lei de Hooke. No equilíbrio as únicas forças que atuam são a força elástica, equação (1), e a força peso, equação (2) (Ramalho et al.,2003).

$$
) \text {. }
$$

$$
\vec{P}=m \cdot \vec{g}
$$


Quando a massa é acoplada a mola, ela sofre uma deformação $x$, tal que as únicas forças atuantes, equação (1) e (2), se igualam, resultando na seguinte relação:

$$
x=\frac{m \cdot g}{k}
$$

Se o corpo de massa $\mathrm{m}$ for deslocado de sua posição de equilíbrio, o sistema massa mola irá sofrer uma oscilação. O sistema massa mola vertical, as forças atuantes, no equilíbrio, estão ilustrada na Figura 1.

Figura 1 - Sistema massa mola vertical, em equilíbrio.

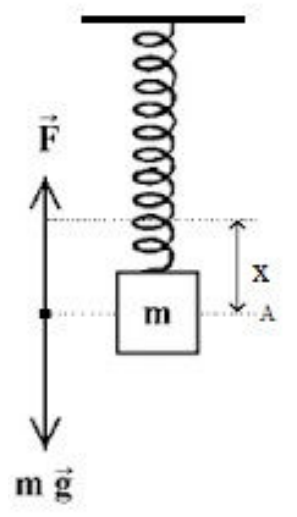

Fonte: Autor

\section{PROCEDIMENTO EXPERIMENTAL}

O equipamento a ser utilizado é um suporte vertical (Conjunto Mecânica-Arete EQ005/Cidepe Produtos - Conjuntos - Conjuntos de Física) conforme Figura 2, no qual uma mola helicoidal é pendurada numa de suas extremidades, estando a outra livre, onde se coloca pesos em formatos de discos de latão com variadas massas.

Nesta extremidade livre, pendura-se um suporte de massa e sobre ele são colocadas diferentes massas, portanto diferentes forças, para produzir diferentes deformações na mola, ou seja, alterar o comprimento da mola. Estes comprimentos são medidos para as diferentes massas colocadas no suporte. Os materiais usados foram: régua milimetrada; uma mola helicoidal; um Conjunto Mecânica-Arete EQ005; uma barra suporte e quatro massas de $0,060 \mathrm{~kg} ; 0,120 \mathrm{~kg} ; 0,180 \mathrm{~kg}$ e $0,240 \mathrm{~kg}$. Monte-se a experiência conforme a Figura 1. Pendure a mola menor na haste de sustentação e ajuste o cursor superior da régua na extremidade superior da mola. Desloque o cursor inferior a fim de medir o comprimento natural da mola, $\mathrm{x}_{0}$. Anotando o valor na folha de questionário com os dados e colocando os dados na Tabela 1 (Nascimento, 2015). Depois, pendurando o suporte de massas na extremidade livre da mola e lendo o novo valor do comprimento da mola, $\mathrm{x}$, ajustando a régua na extremidade da mola e anotando cada valor medido na tabela. 
Figura 2 - Suporte com uma mola e massa (Laboratório de Física Teórica Experimental I).

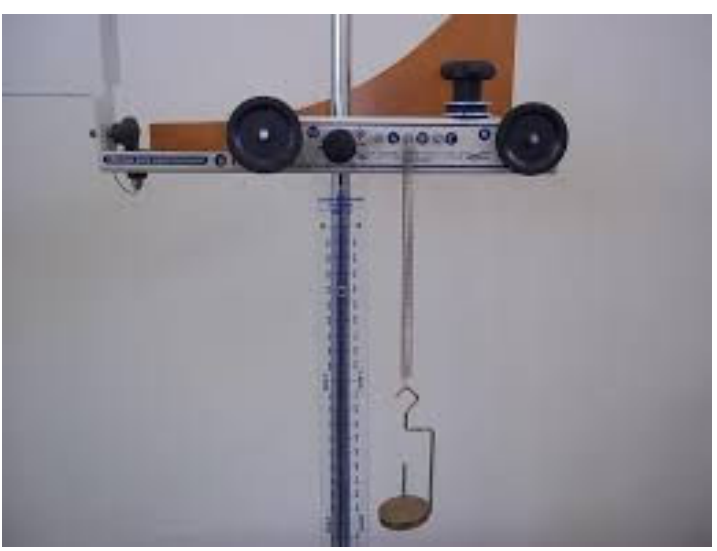

Fonte: Autor

\section{RESULTADOS E DISCUSSÃO}

Por meio dos dados da Tabela 1, plotou-se o gráfico, descrito na Figura 3, que relaciona a dependência da força $(\mathrm{N})$ versus o deslocamento x. Observamos que na Figura 3, obtida pelo programa Origin 8, pelo ajuste linear dos dados da Tabela 1,notamos que devido a sua linearidade, é uma equação da reta, obedecendo diretamente a lei de Hooke, relaciona à elasticidade de corpos, que serve para calcular a deformação causada pela força exercida sobre um corpo, tal que a força é igual ao deslocamento da massa a partir do seu ponto de equilíbrio vezes a característica constante do corpo é deformada.

\begin{tabular}{c|ccccc}
\hline$N^{o}$ & $m(\mathrm{~kg})$ & $F(N)$ & $x_{0}(m)$ & $x_{f}(m)$ & $x \mathbf{( m )}$ \\
\hline 1 & 0,060 & 0,5892 & 0,01 & 0,093 & 0,083 \\
2 & 0,120 & 1,1784 & 0,01 & 0,178 & 0,168 \\
3 & 0,180 & 1,7676 & 0,01 & 0,258 & 0,248 \\
\hline $\mathbf{4}$ & 0,240 & 2,3568 & 0,01 & 0,344 & 0,334 \\
\hline
\end{tabular}

Tabela 1 - Dados do deslocamento $x$, com suas respectivas massas e constante elástica. Fonte: Autor. 
Figura 3 - Gráfico da força versus o deslocamento x, conforme dados da tabela 1.

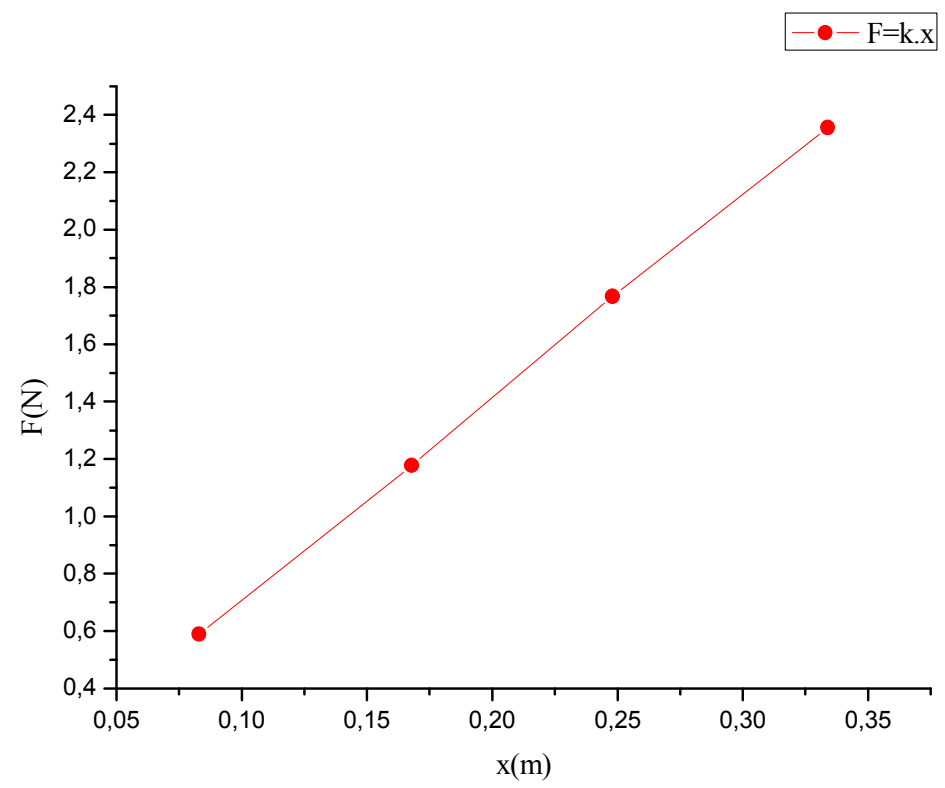

Fonte: Autor

\section{CONCLUSÃO}

Neste relatório, apresentamos os resultados do estudo do comportamento de um sistema massa-mola para a verificação da Lei de Hooke. De acordo com a Tabela 1 e Figura 2 o gráfico apresentado foi possível perceber que entre o deslocamento e a massa existe uma relação linear e que essas grandezas são proporcionais. Alguns fatores externos podem ter causado flutuação aos resultados, como o peso do suporte que sustenta as massas a mola, que considera desprezível. Outro fator relevante é o tempo de vida da mola usada, que por ser usada por vários estudantes, já podem ter alteração no valor da constante elástica.

\section{AGRADECIMENTOS}

Os autores agradecem ao CNPq e ao Departamento de Engenharia Civil/Estácio-Unioul. 


\section{REFERÊNCIAS}

LABURÚ, C. E.;ALMEIDA, C.J. Lei de Hooke: uma comparação entre sistemas lineares. Caderno Catarinense de Ensino de Física 15(1). pp.71-81,1998.

BONJORNO, J. R., BONJORNO, R. A., BONJORNO, V., RAMOS, C. M. Física Fundamental. Volume Único. São Paulo. Ed. FTD. 1999.

HALLIDAY, D.; RESNICK, R.; E. WALKER, J. Fundamentos da Física: Mecânica. V. 1. 4ª.Ed.- Rio de Janeiro: Livros Técnicos e Científicos.pp.138-139, 1996.

NASCIMENTO, L. Modelos de Relatórios: Mecânica. 1 ${ }^{\text {a }}$. Ed.- João Pessoa-PB. pp.1-20, 2015.

RAMAlho, F. J.; FERraro, N. G.; SOARES, P. A. T. Os Fundamentos da Física . São Paulo: Moderna, pp.1-300,2003. 